\title{
Experimental implementation a PWM strategy for dual three- phase PMSM using 12-sector vector space decomposition applied on electric ship propulsion
}

\author{
Mhammed Hasoun ${ }^{1}$, Aziz El Afia ${ }^{2}$, Mohamed Khafallah ${ }^{3}$, Karim Benkirane ${ }^{4}$ \\ ${ }^{1,3,4}$ Departement of Electrical Engineering, Hassan II University, National High School of Electricity and Mechanics \\ "ENSEM", Morocco \\ ${ }^{2}$ Departement of Electrical Engineering, Hassan II University, National High School of Arts and Crafts "ENSAM", \\ Morocco
}

\begin{abstract}
Article Info
Article history:

Received Feb 25, 2020

Revised Apr 26, 2020

Accepted Jul 22, 2020

\section{Keywords:}

Current harmonics Digital signal processor DTP-PMSM

Electric ship propulsion

Space vector modulation

Vector space decomposition

ABSTRACT

The current paper aims at presenting and examining an implementation on a digital signal processor (DSP) of the conventional space vector pulse width modulation (CSVPWM) so as to control the dual three phase permanent magnet synchronous motors (DTP-PMSM) drives applied on electric ship propulsion. It is also an attempt to accomplish a developed control of this technique based on vector space decomposition (VSD) strategy. By this strategy, the analysis and the control of the machine are achieved in three two-dimensional orthogonal subspaces. Among the 12 voltage vectors having maximum, the conventional technique namely the adjacent two-vectors $(12 \mathrm{SA} 2 \mathrm{~V})$ is chosen. Thereby, the test platform allows the implementation of the chosen vectors which are modeled on MATLAB/Simulink using block diagrams and the automatically generated code which is targeted in the DSP card processor. Simulation and experimental results have exposed the efficiency of the proposed test bench of $5 \mathrm{KW}$ prototype machine by using a low-cost TMS32F28379D.
\end{abstract}

This is an open access article under the CC BY-SA license.

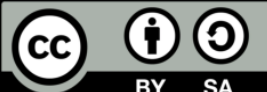

\section{Corresponding Author:}

Mhammed Hasoun,

Departement of Electrical Engineering,

Hassan II University,

National High School of Electricityand Mechanics "ENSEM”, Casa, Morocco.

Email: mhammedhasoun@gmail.com

\section{INTRODUCTION}

Since the 1980s, the introduction of electric propulsion systems for use in ships offers various advantages. This electric propulsion has various benefits that are ships maneuverability, maintenance and acoustic noise. Several researchs relating to the electric propulsion system have been addressed to minimize the occurrence of marine environmental pollution and maintenance costs in civil and military ships. Therefore, electric propulsion has seen a remarkable development in the last years and many ships are now electrically propelled equiped $[1,2]$.

Multiphase machine drives have many improvements over three-phase machine drives like lower torque pulsations, harmonic currents and higher reliability. Effectively, the increase of the number of phases allows a segmentation of the power and hence a reduction of the voltages switched to a given current, where high performance requirements are more needed. Multiphase drives are existing in the maritime domain, automobile, and avionics [3-10]. The most used type of multiphase drives is the dual-three phase (DTP) 
machines. These are distinguished by a multiphase structure within the same stator frame such as two stars having similar characteristics which are spatially shifted by 30 electrical degrees [1].

Permanent magnet synchronous motors (PMSM) have been widely examined as viable solution for variable velocity electric drives ship propulsion notably. Nowadays, the use of multiphase PMSM has become widely used in the training of high-power systems. Among these machines, dual three phase permanent magnet synchronous motors (DTP-PMSM) has been used in many applications like electric propulsion. It has a high defect toleration and dependability $[8,11]$. Nevertheless, the machines concerned have considerable harmonic content while being supplied by a pulse width modulation (PWM) inverter.

Spatial modulation namely space vector PWM (SVPWM) control using the vector space decomposition theory (VSD) is mainly used in recent control of DTP-PMSM and induction machines to get sinusoidal waveforms at the inverter outputs [12-17]. This technique is examined and developed in this paper. Under this control approach, the model of the overall machine, for instance; fundamental, harmonic and components of zero sequence, is changed and divided into three decoupled subspaces and inscribed in three separate space coordinates, marked and nominated in the order given as, $(\alpha, \beta)$ : the subspace of torquecomponent, $\left(\mathrm{z}_{1}, \mathrm{z}_{2}\right)$ : the subspace of harmonic-component and $\left(\mathrm{O}_{1}, \mathrm{O}_{2}\right)$ : the subspace of zero-sequence [1, 18-23]. The main components and its harmonics take part in the conversion of the energy of electromechanical. While, the current components $\left(\mathrm{z}_{1}, \mathrm{z}_{2}\right)$ and $\left(\mathrm{o}_{1}, \mathrm{o}_{2}\right)$ do not participate to the change of the energy of electromechanical. Therefore, the stator resistance and the leakages inductance symbolize the only obstacle [24-26]; similarly, the additional harmonic currents generate only stator losses.

In this paper conventional modulation based on the choice of adjacent two-vectors $(12 \mathrm{SA} 2 \mathrm{~V})$ is proposed with SVPWM control of DTP-PMSM using 12-sector VSD applied on electric ship propulsion [27-28]. The purpose is to get an implementation on DSP. In order to justify the simulation results, an experimental test, is fulfilled. What remains of present work is organised as follows: Section 2 deals with the machine model which will be shown based on VSD; Section 3 discusses the proposed PWM appoach in detail; Section 4 comprises simulation results; Sections 5-6 discuss the experimental results followed by Conclusion and References.

\section{MACHINE'S DYNAMIC MODEL}

The following two Figures 1 and 2 represent the machine windings structure and their supply sources, these double windings of three-phase stator are shifted in the space, with an electrical angular offset of 30 degrees with two unconnected neutral points [29].

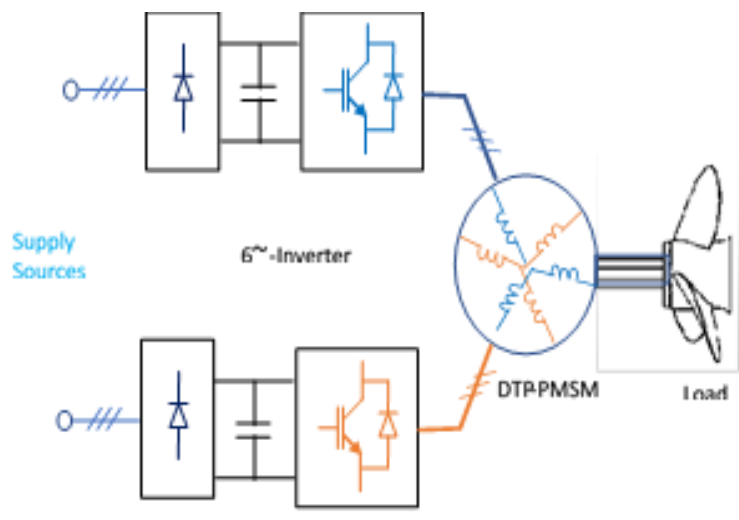

Figure 1. Drive system and its power supply

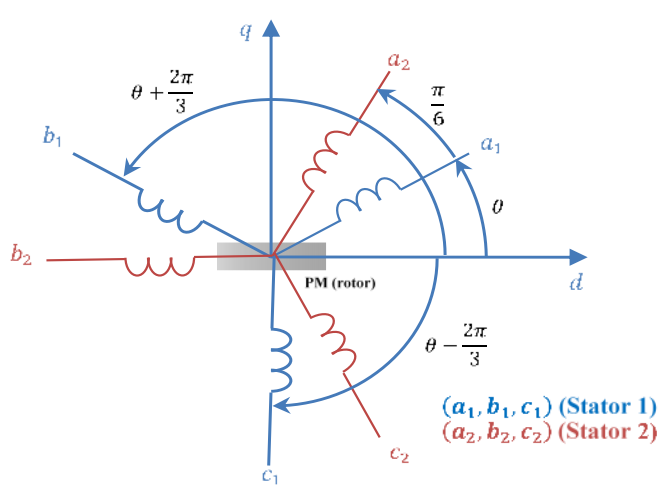

Figure 2. Windings of the machine

Depending on the VSD theory [11], the transformation matrix can be identified by (1). 


$$
T=\frac{1}{\sqrt{3}}\left[\begin{array}{cccccc}
1 & -\frac{1}{2} & -\frac{1}{2} & -\frac{\sqrt{3}}{2} & \frac{\sqrt{3}}{2} & 0 \\
0 & \frac{\sqrt{3}}{2} & -\frac{\sqrt{3}}{2} & \frac{1}{2} & \frac{1}{2} & -1 \\
1 & -\frac{1}{2} & -\frac{1}{2} & -\frac{\sqrt{3}}{2} & \frac{\sqrt{3}}{2} & 0 \\
0 & -\frac{\sqrt{3}}{2} & \frac{\sqrt{3}}{2} & \frac{1}{2} & \frac{1}{2} & -1 \\
1 & 1 & 1 & 0 & 0 & 0 \\
0 & 0 & 0 & 1 & 1 & 1
\end{array}\right]
$$

By means of the above matrix conversion, the difficult motor system is divided into three mutually decoupled orthogonal subspaces $(\alpha-\beta),\left(\mathrm{z}_{1}, \mathrm{z}_{2}\right)$ and $\left(\mathrm{o}_{1}, \mathrm{o}_{2}\right)$. The variables equations caracterizing the machine, according to the indicated suppositions in [16], can be specified in stationary model by:

$$
\begin{aligned}
& {\left[V_{\alpha \beta}\right]=\left[R_{S}\right]\left[i_{\alpha \beta}\right]+\frac{\mathrm{d}}{\mathrm{dt}}\left[\Psi_{\alpha \beta}\right]=\left[R_{S}\right]\left[i_{\alpha \beta}\right]+\frac{\mathrm{d}}{\mathrm{dt}}\left[\left[L_{\alpha \beta}\right]\left[i_{\alpha \beta}\right]+\Psi_{\mathrm{PM}} \cdot\left[\begin{array}{c}
\cos \theta \\
\sin \theta
\end{array}\right]\right]} \\
& {\left[V_{z_{1,2}}\right]=\left[R_{S}\right]\left[i_{z_{1,2}}\right]+\frac{\mathrm{d}}{\mathrm{dt}}\left[\Psi_{z_{1,2}}\right]=\left[R_{S}\right]\left[i_{z_{1,2}}\right]+\left[L_{z}\right] \frac{\mathrm{d}}{\mathrm{dt}}\left[i_{z_{1,2}}\right]} \\
& {\left[V_{o_{1,2}}\right]=\left[R_{S}\right]\left[i_{o_{1,2}}\right]+\frac{\mathrm{d}}{\mathrm{dt}}\left[\Psi_{o_{1,2}}\right]=\left[R_{S}\right]\left[i_{o_{1,2}}\right]+\left[L_{o}\right] \frac{\mathrm{d}}{\mathrm{dt}}\left[i_{o_{1,2}}\right]}
\end{aligned}
$$

Where:

- $\left(\mathrm{L}_{\mathrm{d}}, \mathrm{L}_{\mathrm{q}}\right)$ : Direct and indiret inductances;

- $\left(\mathrm{L}_{\mathrm{z}}, \mathrm{L}_{\mathrm{o}}\right)$ : Transformed of inductances conventional and mutual leakage;

- $\left(\Psi_{\mathrm{PM}}\right) \quad$ : Permanent magnet flux;

$-(\Theta) \quad$ : Rotor position.

The current components in the $(\alpha-\beta)$ subspace contribute to the conversion of electromechanical. Nevertheless, the variables of current in $\left(\mathrm{z}_{1}, \mathrm{z}_{2}\right)$ and $\left(\mathrm{o}_{1}, \mathrm{o}_{2}\right)$ do not participate effectively in the conversion of electromechanical which generates losses of stator. The conversion matrix should be used to illustrate the immobile $(\alpha, \beta)$ plane in the revolving plane $(d, q)$ which is presented as follows [30]:

$$
T_{r}=\left[\begin{array}{ccc}
\cos \theta & \sin \theta & 0 \\
-\sin \theta & \cos \theta & 0 \\
0 & 0 & I_{4}
\end{array}\right]\left(I_{4}: \text { four-dimentional unit matrix }\right)
$$

In the (d-q) plane, the electric and the mechanic equations of the machine are expressed as follows:

$$
\begin{gathered}
\left.\left[\begin{array}{c}
\mathrm{V}_{\mathrm{d}} \\
\mathrm{V}_{\mathrm{q}}
\end{array}\right]=\left[\begin{array}{cc}
\mathrm{R}_{\mathrm{s}} & 0 \\
0 & \mathrm{R}_{\mathrm{s}}
\end{array}\right]\left[\begin{array}{l}
\mathrm{i}_{\mathrm{d}} \\
\mathrm{i}_{\mathrm{q}}
\end{array}\right]+\frac{\mathrm{d}}{\mathrm{dt}}\left[\begin{array}{c}
\Psi_{\mathrm{d}} \\
\Psi_{\mathrm{q}}
\end{array}\right]+\frac{d \theta}{d t}\left[\begin{array}{c}
-\Psi_{\mathrm{q}} \\
\Psi_{\mathrm{d}}
\end{array}\right]=\left[\begin{array}{cc}
\mathrm{R}_{\mathrm{s}} & 0 \\
0 & \mathrm{R}_{\mathrm{s}}
\end{array}\right]\left[\begin{array}{c}
\mathrm{i}_{\mathrm{d}} \\
\mathrm{i}_{\mathrm{q}}
\end{array}\right]+\frac{\mathrm{d}}{\mathrm{dt}}\left[\begin{array}{cc}
\mathrm{L}_{\mathrm{D}} & 0 \\
0 & \mathrm{~L}_{\mathrm{Q}}
\end{array}\right]\left[\begin{array}{c}
\mathrm{I}_{\mathrm{D}} \\
\mathrm{I}_{\mathrm{Q}}
\end{array}\right]+\sqrt{3}\left[\begin{array}{c}
\Psi_{\mathrm{PM}} \\
0
\end{array}\right]\right]+\frac{d \theta}{d t}\left[\begin{array}{c}
-\Psi_{\mathrm{q}} \\
\Psi_{\mathrm{d}}
\end{array}\right] \\
\Gamma_{e m}=p\left(i_{q} \Psi_{\mathrm{d}}-i_{d} \Psi_{\mathrm{q}}\right) \quad(p: \text { Number pair poles })
\end{gathered}
$$

\section{RESEARCH METHOD}

\subsection{SVPWM strategy for DTP- PMSM}

In machine drives control, the current approach tends to define the $(\alpha-\beta)$ frame as being the reference of the stator voltage vector produced by the control system. After that, the harmonics coming out in the planes $\left(\mathrm{Z}_{1}-\mathrm{Z}_{2}\right)$ and $\left(\mathrm{o}_{1}, \mathrm{O}_{2}\right)$ only generate losses. To minimize these harmonics, the middling voltage vectors generated in the two planes should be zero [31]. The following equation can express the phase voltages:

$$
\left[\begin{array}{l}
V_{a 1} \\
V_{b 1} \\
V_{c 1} \\
V_{a 2} \\
V_{b 2} \\
V_{c 2}
\end{array}\right]=\frac{\mathrm{E}}{3}\left[\begin{array}{cccccc}
2 & -1 & -1 & 0 & 0 & 0 \\
-1 & 2 & -1 & 0 & 0 & 0 \\
-1 & -1 & 2 & 0 & 0 & 0 \\
0 & 0 & 0 & 2 & -1 & -1 \\
0 & 0 & 0 & -1 & 2 & -1 \\
0 & 0 & 0 & -1 & -1 & 2
\end{array}\right]\left[\begin{array}{l}
S_{a 1} \\
S_{b 1} \\
S_{c 1} \\
S_{a 2} \\
S_{b 2} \\
S_{c 2}
\end{array}\right]
$$

While $\left(\mathrm{S}=\mathrm{S}_{\mathrm{a} 1}, \mathrm{~S}_{\mathrm{b} 1}, \mathrm{~S}_{\mathrm{c} 1}, \mathrm{~S}_{\mathrm{a} 2}, \mathrm{~S}_{\mathrm{b} 2}, \mathrm{~S}_{\mathrm{c} 2}\right)$ are the states of switch, $\mathrm{E}$ is the continuous bus. 
According to relationship (1), the voltage vectors expressed in the two referentials can be specified by the following relationship:

$$
\left[\begin{array}{llllll}
V_{\alpha} & V_{\beta} & V_{z 1} & V_{z 2} & V_{01} & V_{02}
\end{array}\right]^{T}=T\left[\begin{array}{llllll}
V_{a 1} & V_{b 1} & V_{c 1} & V_{a 2} & V_{b 2} & V_{c 2}
\end{array}\right]^{T}
$$

The machine drive comprises 64 diverse voltage vectors. A number of decimals is matching to binary

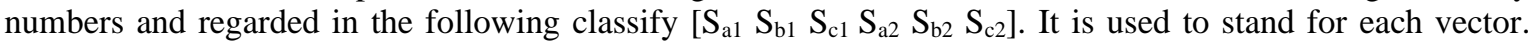
Consequently, in the submodels $(\alpha-\beta)$ and $\left(z_{1}-z_{2}\right)$, there are 60 vectors with non null voltage and 4 null ones $(0,7,56,63)$ which are expressed in two Figures 3 and 4 [32].

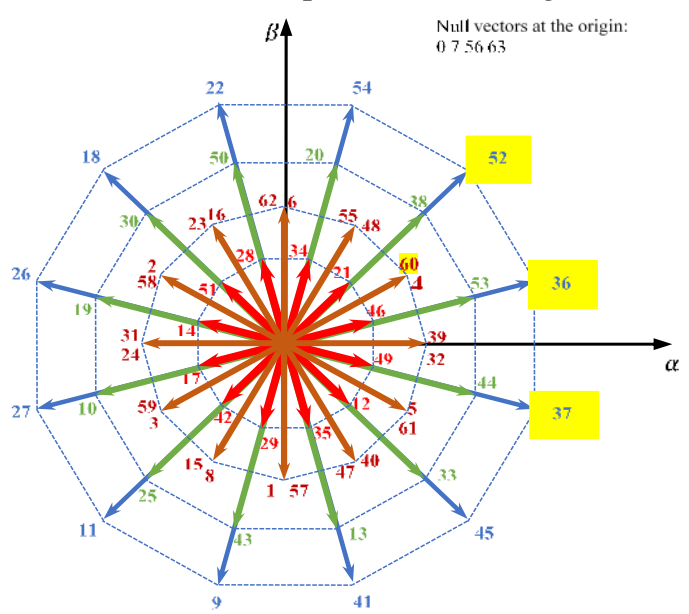

Figure 3. Illustration of space vectors using VSD in $(\alpha-\beta)$

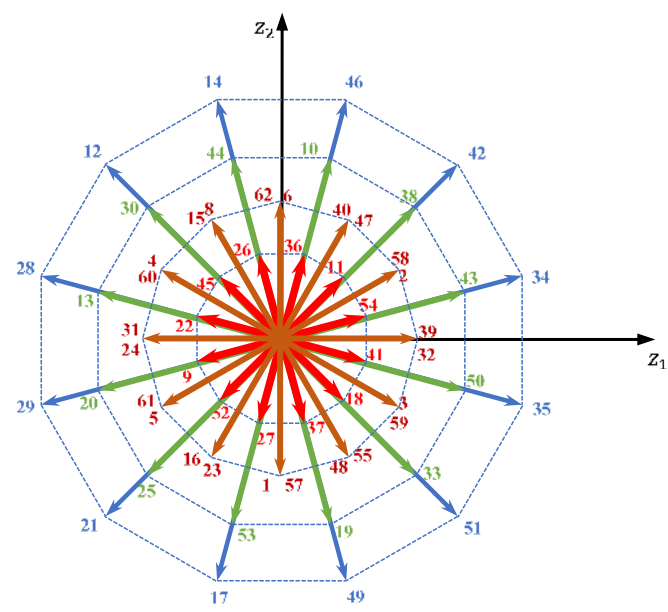

Figure 4. Illustration of space vectors using VSD in $\left(\mathrm{z}_{1}-\mathrm{z}_{2}\right)$

According to the two above figures, the $(\alpha-\beta)$ vectors of voltage can be divided into four dodecagons with diverse amplitudes (from innermost to outermost: $\mathrm{D}_{1}, \mathrm{D}_{2}, \mathrm{D}_{3}, \mathrm{D}_{4}$ ) [33] which are expressed as follows:

$$
\left\{\begin{array}{c}
U_{D 1}=\frac{\sqrt{(2-\sqrt{3})}}{\sqrt{3}} E \\
U_{D 2}=\frac{1}{\sqrt{3}} E \\
U_{D 3}=\frac{\sqrt{2}}{\sqrt{3}} E \\
U_{D 4}=\frac{\sqrt{(2+\sqrt{3})}}{\sqrt{3}} E
\end{array}\right.
$$

The voltage vectors, having an utmost magnitude in the $(\alpha-\beta)$ subspace, will have a smallest magnitude in the $\left(z_{1}-z_{2}\right)$ subspace; however, the others retain the same magnitude.

\subsection{2-Sector conventional modulation (12SA2V)}

In this strategy, the 12 and the 24 voltage vectors which have respectively highest and half amplitude share the $(\alpha-\beta)$ subspace into 24 sectors. The vectors of voltage chosen allow to obtain the minimum amplitude vectors in the $\left(\mathrm{z}_{1}-\mathrm{z}_{2}\right)$ subspace, which warranties the least current content of harmonics in the $\left(\mathrm{Z}_{1}-\mathrm{Z}_{2}\right)$ subspace. Therefore, contributee to the minimization of losses [3].

The vectors of voltage having highest magnitude (45-37-36-52-54-22-18-26-27-11-9-41) allow synthetizing the reference voltage vector $V_{\text {ref }}$ as shown in Figure 5. In accordance with the site of the reference voltage vector $V_{\text {ref }}$ in the $(\alpha-\beta)$ subspace as shown in Figure 3, this idea is the same as the conventional method. Just two adjacent voltages are employed to synthesize the reference voltage vector $V_{\text {ref }}$. Take the example where the reference voltage vector is placed in sector $\mathrm{S}_{1}$, the two attached voltage vectors (37-36) and null voltage vectors (7-56) are used. The period corresponding to each voltage vector is defined by the relationship as follows: 


$$
\left[\begin{array}{cc}
v_{\alpha}^{1} & v_{\alpha}^{2} \\
v_{\beta}^{1} & v_{\beta}^{2}
\end{array}\right]\left[\begin{array}{l}
t_{1} \\
t_{2}
\end{array}\right]=T_{s}\left[\begin{array}{l}
V_{\text {ref } \alpha} \\
V_{\text {ref } \beta}
\end{array}\right]
$$

Where:

$T_{S} \quad$ : Sample time;

$\mathrm{t}_{1}$ and $\mathrm{t}_{2}$ : Periods matching to the two voltage vectors;

$V_{X}^{k} \quad$ : Projection of $k^{\text {th }}$ voltage vector under the $\mathrm{x}$-axis $\left(\mathrm{x}=\alpha, \beta, \mathrm{z}_{1}, \mathrm{z}_{2}\right)$.

The period interval assigned to zero voltage vectors is the residual time:

$$
t_{0}=T_{s}-\left(t_{1}+t_{2}\right)
$$

So as to nearly allow the realization during each PWM period of two transitions, the zero vectors are intentionally situated at the commencement, the medium and at the finish of the switching sequence via the succeeding arrangement $\left(\mathrm{V}_{0}-\mathrm{V}_{1}-\mathrm{V}_{2}-\mathrm{V}_{0}-\mathrm{V}_{2}-\mathrm{V}_{1}-\mathrm{V}_{0}\right)$ as shown in Figure 6. If the same reflexion is applied to the other sectors, the periods of two non-null vectors are determined in Table 1.

The projection of the vectors of voltage on the $(\alpha-\beta)$ and $\left(z_{1}-z_{2}\right)$-axis in the relationship (11), allows to determine the coefficients mentioned in the Table 1.

$$
\left[\begin{array}{l}
T_{1} \\
T_{2} \\
T_{3} \\
T_{4} \\
T_{5} \\
T_{6}
\end{array}\right]=\frac{T_{s}}{K}\left[\begin{array}{cc}
1 & -(\sqrt{3}+2) \\
(\sqrt{3}+1) & (\sqrt{3}+2) \\
-(\sqrt{3}+1) & (\sqrt{3}+1) \\
(\sqrt{3}+2) & (\sqrt{3}+1) \\
(\sqrt{3}+2) & -1
\end{array}\right]\left[\begin{array}{l}
v_{\text {ref }} \\
v_{\text {ref }}
\end{array}\right]\left(K=E \cdot \frac{(2 \sqrt{3}+3)}{3}\right)
$$

The (12) allows to establish the period assigned to null vectors of voltage. The finishing switching sequences for all sectors, where just the null voltage vectors 7 and 56 are used, are shown in the below Table 2 .

Table 1. 12-Sector PWM Vectors applying Times $\left(\mathrm{S}_{1}-\mathrm{S}_{6}\right)$

\begin{tabular}{|c|c|c|c|c|c|c|c|c|c|c|c|c|c|}
\hline & \multicolumn{12}{|c|}{ SECTORS } \\
\hline & & $\mathrm{S}_{1}$ & $\mathrm{~S}_{2}$ & $\mathrm{~S}_{3}$ & $\mathrm{~S}_{4}$ & $\mathrm{~S}_{5}$ & $\mathrm{~S}_{6}$ & $\mathrm{~S}_{7}$ & $\mathrm{~S}_{8}$ & $\mathrm{~S}_{9}$ & $\mathrm{~S}_{10}$ & $\mathrm{~S}_{11}$ & $S_{12}$ \\
\hline \multirow{4}{*}{ VECTORS } & $\mathrm{V}_{01}$ & 7 & 7 & 7 & 7 & 7 & 7 & 7 & 7 & 7 & 7 & 7 & 7 \\
\hline & $\mathrm{V}_{1}$ & 37 & 36 & 54 & 22 & 22 & 18 & 27 & 11 & 11 & 9 & 45 & 37 \\
\hline & $\mathrm{V}_{2}$ & 36 & 52 & 52 & 54 & 18 & 26 & 26 & 27 & 9 & 41 & 41 & 45 \\
\hline & $\mathrm{V}_{02}$ & 56 & 56 & 56 & 56 & 56 & 56 & 56 & 56 & 56 & 56 & 56 & 56 \\
\hline
\end{tabular}

\begin{tabular}{cccccccc}
\hline & & \multicolumn{5}{c}{ SECTORS } \\
\hline \multirow{2}{*}{ TIMES } & $\mathrm{S}_{1}$ & $\mathrm{~S}_{2}$ & $\mathrm{~S}_{3}$ & $\mathrm{~S}_{4}$ & $\mathrm{~S}_{5}$ & $\mathrm{~S}_{6}$ \\
& $\mathrm{t}_{1}$ & $\mathrm{~T}_{1}$ & $\mathrm{~T}_{3}$ & $\mathrm{~T}_{4}$ & $-\mathrm{T}_{5}$ & $\mathrm{~T}_{3}$ & $\mathrm{~T}_{2}$ \\
& $\mathrm{t}_{2}$ & $\mathrm{~T}_{2}$ & $-\mathrm{T}_{1}$ & $\mathrm{~T}_{5}$ & $\mathrm{~T}_{6}$ & $-\mathrm{T}_{6}$ & $-\mathrm{T}_{3}$ \\
\hline
\end{tabular}

Table 2. 12-Sector PWM switching sequences $\left(\mathrm{S}_{1}-\mathrm{S}_{12}\right)$

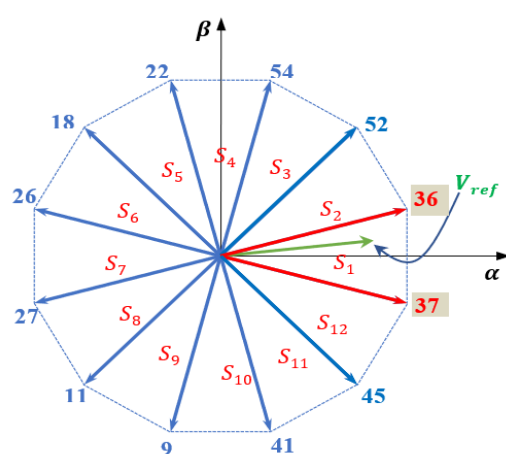

Figure 5. Illustration of 12 maximum magnitude in $(\alpha-\beta)$

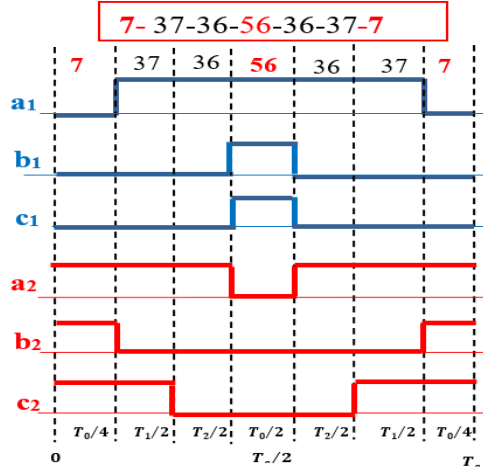

Figure 6. Sequence of switching in sector 1 in $(\alpha-\beta)$ 


\section{RESULTS AND DISCUSSION}

\subsection{MATLAB/Simulink Simulation}

In the third section, the approach suggested will be reasonably investigated via Matlab/Simulink environment and experimental test. The principal characteristics of the DTP-PMSM, through a $5 \mathrm{KW}$ model machine for ship propulsion are enumerated in the simulation tests provided in Table 3. According to the simulation results, the load torque is set at $15 \mathrm{~N} . \mathrm{m}$, the machine velocity is maintained at $300 \mathrm{rpm}$ and the drive switching frequency is fixed at $5 \mathrm{kHz}$. The Figures 7 to 10 illustrate the simulation tests of the exposed approach.

As it can be seing from the simulation results, we can notice that the current of stator phase is not purely sinusoidal and that the large current harmonic appears in motor phase current for the conventional SVPWM technique as shown in Figures 7-8. In fact, the phase current, has a great quantity of the $5^{\text {th }}$ and the $7^{\text {th }}$ order harmonics of current that are dominant. The total harmonic distortion (THD) is $63.7 \%$. Conversely, the amplitude of the $5^{\text {th }}$ and the $7^{\text {th }}$ order current harmonics is extremely important. It is worth pointing out that these constituents of stator current do not participate to the air gap flux and will simply cause energy losses. Figure 9 stands for the currents in $(\alpha-\beta)$ subspace which have a smooth and a normal trajectory for this method. The response of velocity is showed in Figure 10; the speed gets its mention with good static and dynamic presentation.

Table 3. Machine's principal components

\begin{tabular}{cc}
\hline Designation & Value/ unit \\
\hline DC continous bus : $\mathrm{E}$ & $200 \mathrm{~V}$ \\
Resistance of stator : $\mathrm{R}_{\mathrm{s}}$ & $1.096 \Omega$ \\
Inductance directe $: \mathrm{L}_{\mathrm{d}}$ & $8.45 \mathrm{mH}$ \\
Inductance quadrature $: \mathrm{L}_{\mathrm{q}}$ & $8.45 \mathrm{mH}$ \\
Flux of permanent magnet : $\Psi_{\mathrm{PM}}$ & $0.184 \mathrm{~Wb}$ \\
Moment of total inertia: $\mathrm{J}$ & $93.10^{-3} \mathrm{kgm}^{2}$ \\
Coefficient of total viscous friction : $\mathrm{f}$ & $0.01 \mathrm{Nms} / \mathrm{rad}$ \\
Pair poles number: $\mathrm{p}$ & 3 \\
\hline
\end{tabular}

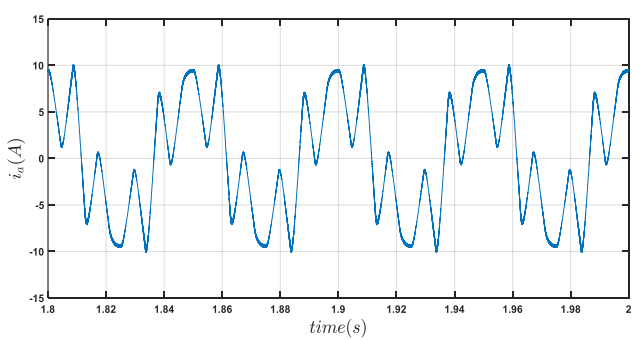

Figure 7. Stator phase current

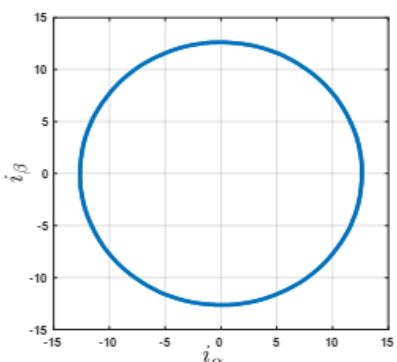

(a)

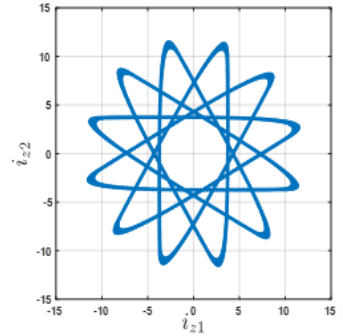

(b)

Figure 9. Trajectory of space current vectors in two

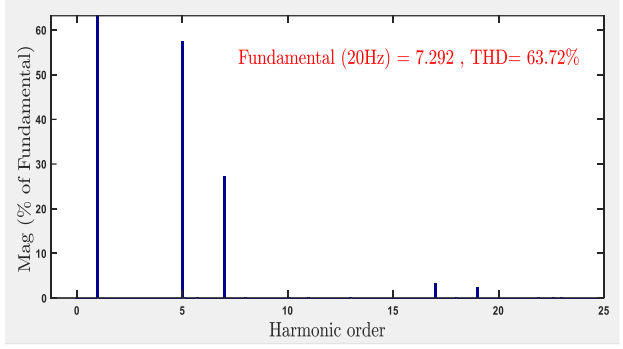

Figure 8. Harmonic analysis (FFT)

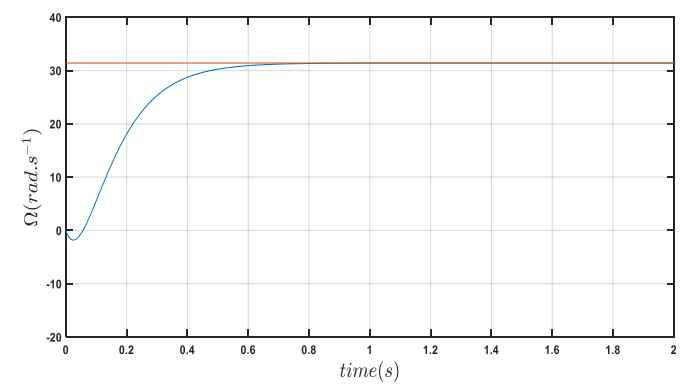

Figure 10. Machine's speed subspaces: (a) $(\alpha-\beta)$ and (b) $\left(\mathrm{z}_{1}-\mathrm{z}_{2}\right)$ 


\subsection{Experimental Based on TMS320F28379D}

So as to approve the possibility of the recommended SVPWM technique, a set of tests is fulfilled. The photograph of experimental results is shown in Figure 11. This latter is consisting of a dual three phase voltage source inverter (VSI) supplying a $5 \mathrm{KW}$ experimental setup machine, and the entire control strategy is tested on a DSP TMS320F28379D card processor. In fact, it is feasible to apply the 12-sector PWM technique related to the implemented SVPWM technique.

The experimental results which use conventional technique with the similar characteristics and working conditions like those of tests, are expressed in Figures 12-14. Figures 12 and 13 are the experimental tests equivalent to the simulation results of Figures 7 and 8, respectively. Figure 14 is the experimental result equivalent to the simulation result of Figure 10. There is a reliable association between the experiments and the simulations results. The suggested PWM strategy is successfully experimented and the resulting assumptions can be drawn from these experimental tests: In this technique, the phase current is not purely sinusoidal and has a harmonics great quantity, the $5^{\text {th }}$ and the $7^{\text {th }}$ particularly. The latter two, appearing in the $\left(\mathrm{Z}_{1}-\mathrm{Z}_{2}\right)$ subspace, are very large because and cause signal distortion due to the absence of control over currents in the $\left(\mathrm{z}_{1}-\mathrm{Z}_{2}\right)$ subspace. This shows the feasibility of the suggested strategy.

Figure 14 illustrates the machine velocity under the double open loop control strategy. It also indicates the rapid speed response of the control system. This stabilizes at a 300-rpm value.

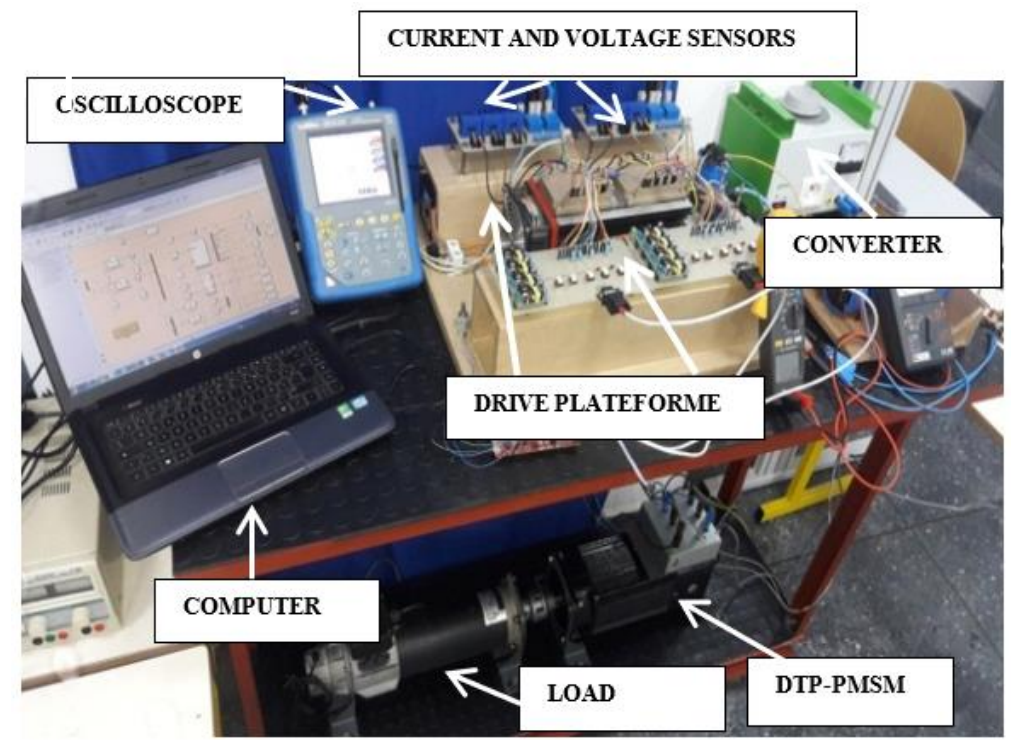

Figure 11. Photograph of experimental test bench

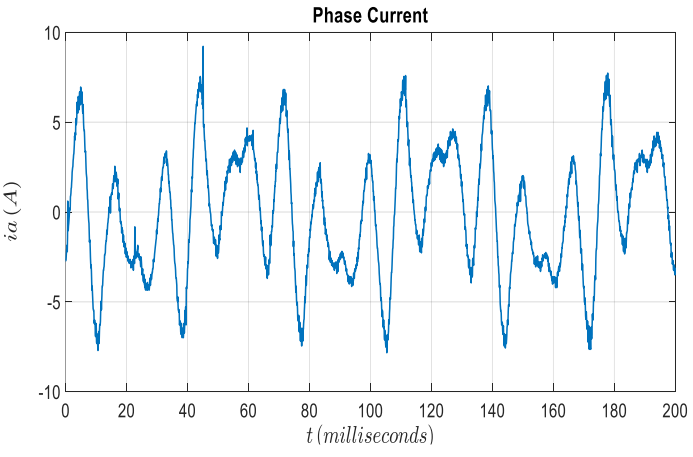

Figure 12. Experimental of stator phase current

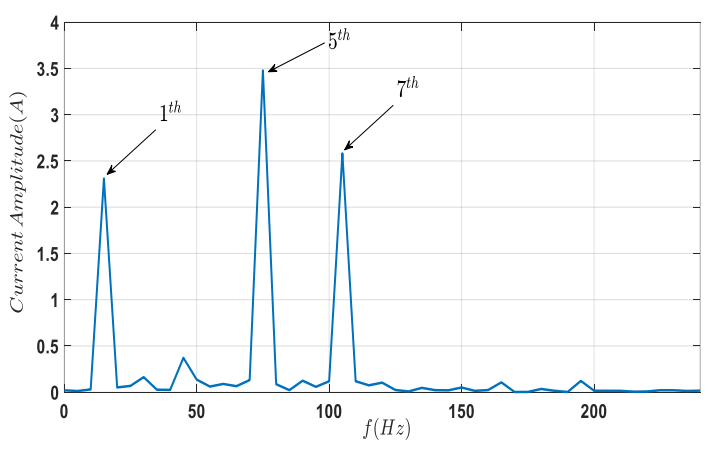

Figure 13. Experimental of harmonic analysis (FFT) 


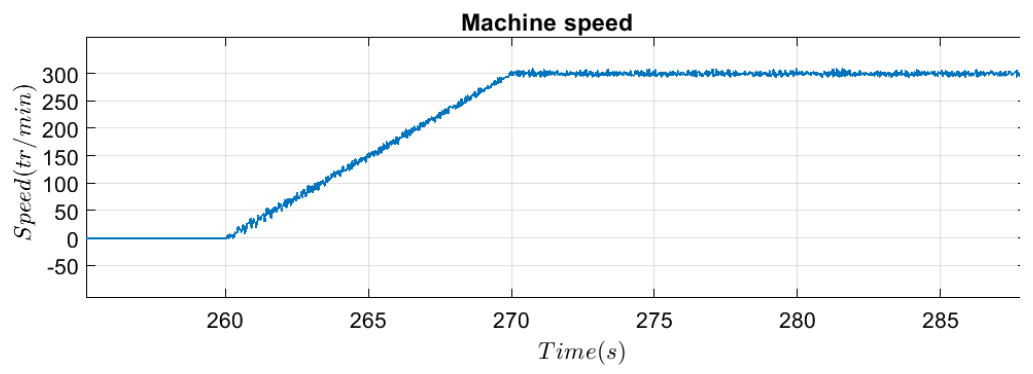

Figure 14. Experimental of machine's speed

\section{CONCLUSION}

The principal goal of the suggested work is to carry out an implementation on SVPWM conventional method to control the DTP-PMSM drives. In fact, the SVPWM using the conventional adjacent two voltage vectors $(12 \mathrm{SA} 2 \mathrm{~V})$ modulation has been presented under stator current total harmonic distortion (THD). After that, this method has been applied on DSP board TMS32F28379D. In the tests, the sensor of current is sampled by the control of open-loop. As deduced from the simulation results, the conventional SVPWM control based on vector space decomposition gives reasonable results regarding the experimental tests. It has been confirmed that the suggested method can be easily implemented digitally versus other methods using four voltage vectors whose implementation will be the subject of a future article. The farther investigation will concentrate on the detailed experimentations for the DTP-PMSM.

\section{REFERENCES}

[1] M.Hasoun, A.El Afia, K.Chikh, M.Khafallah and K.Benkirane, "A PWM Strategy for Dual Three-Phase PMSM Using 12-Sector Vector Space Decomposition for Electric Ship Propulsion," 2018 19th IEEE Mediterranean Electrotechnical Conference (MELECON), Mai 2-7, IEEE, pp.243-248, 2018.

[2] Yi Guo and Xuekui Yan, "Research on matrix converter control multi-phase PMSM for all electric ship", 2011 International Conference on Electrical and Control Engineering, pp.3120-3123, 2011.

[3] H. Echeikh, R. Trabelsi, H. Kesraoui, A. Iqbal and M.F. Mimouni, "Torque ripples improvement of direct torque controlled five-phase induction motor drive using backstepping control," International Journal of Power Electronics and Drive Systems, (IJPEDS), Vol. 11, No. 1, pp.64-74, March 2020.

[4] A. Taibi, K. Hartani and A. Allali, "New DTC strategy of multi-machines single-inverter systems for electric vehicle traction applications," International Journal of Power Electronics and Drive Systems, (IJPEDS), Vol. 11, No. 2, pp.641-650, June 2020.

[5] E.Levi, "Multiphase electric machines for variable-speed applications," IEEE Trans. Ind. Electron., Vol.55, pp.1893-1909, 2008.

[6] M. M. El Kholy and Z. M. S. El Barbary, "Performance Analysis of indirect rotor field orientation five phase induction motor using eight switch inverters," International Journal of Power Electronics and Drive Systems, (IJPEDS), Vol. 8, No. 3, pp.1128-1138, September 2017.

[7] M.B.R. Corra, C. B. Jacobina, C.R. da Silva, A.N. Lima and E.R.C. da Silva, "Six-phase AC drive system with reduced common-mode voltage", IEEE International Electric Machines and Drives Conference, pp.1852-1858, 2003.

[8] A. K. Mohanty and K. B. Yadav, "Estimation of excitation capacitance requirement of an isolated multi-phase induction generator for power generation," International Journal of Power Electronics and Drive Systems, (IJPEDS), Vol. 7, No. 2, pp.561-567, June 2016.

[9] Drazen Dujic, Atif Iqbal and Emil Levi, "A Space Vector PWM Technique for Symetrical Six-Phase Voltage Source Inverters", EPE Journal, Vol.17, No.1, pp.24-32, 2007.

[10] Yashan Hu, Z. Q. Zhu and Milijana Odavic, "Comparison of Two-Individual current Control and Vector Space Decomposition Control for DualThree-Phase PMSM," IEEE Trans. Ind. Applicat, Vol.53, No.5, Sept. /Oct. 2017, pp.4483- 4492.

[11] Y. Zhao and T. A. Lipo, "Space Vector PWM Control of Dual Three-Phase Induction Machine Using Vector Space Decomposition", IEEE Trans. Ind. Applicat., Vol.31, No.5, pp.1100-1109, 1995.

[12] A. Bendaikha and S. Saad, "Comparative study of five-level and seven-level inverter controlled by Space vector pulse width Modulation," International Journal of Power Electronics and Drive Systems, (IJPEDS), Vol. 8, No. 2, pp.755-766, June 2017.

[13] Bulai Wang, Gu Wei, Jianxin Chu and Guo Yi, "A Novel Modeling for A Dual Three-phase Permanet Magnet Synchronous Machine," $200810^{\text {th }}$. Conf. on Control, Automation, Robotics and Vision, Hanoi, Vietnam, pp. 17-20 December 2008, 2008. 
[14] Yanjun Yu, Lixiao Gao, Yang Liu and Feng Chai, "24-Sector Space Vector Decomposition for a Dual Three-Phase PMSM," $201417^{\text {th }}$ International Conference on Electrical Machines and Systems (ICEMS), oct 22-25, Hangshou, China, pp. 1601-1606, 2014.

[15] H. Yan, Y. Xu, J. Zou and F. Zeng, "Phase current Reconstruction for Dual Three-Phase PMSM Drive in Electric Vehicles Using Two DC Link Current Sensors," 2016 IEEE Vehicle Power and Propulsion Conference (VPPC), pp. 1- 6, 2016.

[16] Ping Zhang, Wei Zhang and Xiaofeng Shen, "Comparative Study of Field-Oriented Control in Different Coordinate Systems for DTP- PMSM,' 2013 International Conference on Electrical Machines and Systems (ICEMS), Oct.26-29, pp.1015-1019, 2013.

[17] K. Yu, H. Guo, Z. Sun and Z. Wu, "Efficiency Optimization Control of Permanent Magnet Synchronous Motor for Electric Propulsion System", International Conference on Electrical Machines and Systems, pp.56-61, 2013.

[18] L Wang, D Zhang, Z. Wang, J.Chen, M.Cheng and N.Ren "Vector Space Decomposition Based Control of Neutral-Point-Clamping (NPC) Three-level Inverters Fed Dual Three-Phase PMSM Drives," IECON 2016- $42^{\text {nd }}$ Annual Conference of the IEEE Industrial Electronics Society, Oct 16, IEEE, pp. 2988-2993, 2016.

[19] Z. Wang, Y. Wang, J. Chen and Y. Hu, "Decoupled Space Decomposition Vector Based Space Vector Modulation for Dual Three-Phase Three-Level Motor Drives," IEEE Trans. Ind. Applicat., Vol.33, No.12, pp. 10683-10697, 2018.

[20] L. Yuan, M.-L. Chen, J.-Q. Shen, and F. Xiao, "Current Harmonics Elimination Control Method for Six-Phase PM Synchronous Motor Drives," ISA Transactions, vol. 59, pp. 443 - 449, 2015.

[21] Valentin Oleschuk et al "Combined PWM Control of Multi-Inverter Installation with Two DC-Links", 2015 International Conference of Electrical Drives and Power Electronics (EDPE), pp. 94 - 98, 2015.

[22] H. Zhang et al, "Study on Series Control Method for Dual Three-Phase PMSM based on Space Vector Pulse Width Modulation", International Journal of Control and Automation Vol. 8, No. 1, pp. 197-210, 2015.

[23] Khoudir Marouani, Lotfi Baghli, Djafar Hadiouche, Abdelaziz Kheloui, and Abderrezak Rezzoug, "A New PWM Strategy Based on a 24-Sector Vector Space Decomposition for a Six-Phase VSI-Fed Dual Stator Induction Motor", IEEE Trans. Ind. Applicat., Vol. 55, No. 5, pp.1910-1920, 2008.

[24] W. Tiejun, S. Chenglin, C. Yongbing and J. Xiaoyi, "Researchon harmonics of multiphase induction motors", Proc. IEEE IEMDC, Antalya, Turkey, Vol. 2, May 3-5, pp.1524-1528, 2007.

[25] K.K.Mohapatra, R.S.Kanchan, M.R.Baiju, P.N.Tekwani and K.Gopakumar, "Independent field-oriented control of two split-phase induction motors from a single six-phase inverter," IEEE Trans. Ind. Electron., Vol. 52, No. 5, pp.1372-1382, Oct. 2005.

[26] R. Bojoi, M. Lazzari, F. Profumo, Senior Member, IEEE, and A. Tenconi, "Digital Field-Oriened Control for Dual Three-Phase Induction Motor Drives", IEEE Transactions on Industry Applications, Vol. 39, No.3, pp. 752-760, 2003.

[27] M. Hasoun, A. El Afia, M. Khafallah and K. Benkirane, "Performance Comparison of Two-SVPWM-Strategies Based Vector Space Decomposition Controlled Dual Three-Phase PMSM for Electric Ship Propulsion”, $20197^{\text {th }}$ International Renewable and Sustainable Energy Conference, (IRSEC), 27-30 November 2019.

[28] M. Hasoun, A. El Afia, M. Khafallah and K. Benkirane, "Field Oriented Control of Dual Three-Phase PMSM Based Space Vector Decomposition for Electric Ship Propulsion", 2019 International Conference of Computer Science and Renewable Energies, (ICCSRE), pp.1-6, 22 August 2019, IEEE/ICCSRE2019, 22-24 July, 2019, Agadir, Morocco.

[29] A. Abden, A. Bouchetta, O. Boughazi, A. Baghdadi and I.K. Bousserhane, "Double Star induction machine using nonlinear integral backstepping control," International Journal of Power Electronics and Drive Systems (IJPEDS), Vol. 10, No. 1, pp.27-40, March 2019.

[30] J. Pradeep and R. Devanathan, "Adoption of Park's Transformation for Inverter Fed Drive", International Journal of Power Electronics and Drive System (IJPEDS), Vol. 5, No. 3, pp. 366 - 373, 2015.

[31] M. Porselvi, R. Bojoi, M. Lazzari, F. Profumo and A. Tenconi, "Digital Field-Oriented Control for Dual ThreePhase Induction Motor Drives", IEEE Trans. Ind. Applicat., Vol.39, No.3, pp.752-760, 2003.

[32] M. Hasoun, A. El Afia, M. Khafallah and K. Benkirane, "Field Oriented Control based on a 24-Sector Vector Space Decomposition for Dual Three-Phase PMSM applied on Electric Ship Propulsion", International Journal of Power Electronics and Drive System (IJPEDS), Vol. 11, No. 3, pp. 1175 - 1187, September 2020.

[33] J. Karttunen, S. Kallio, P. Peltoniemi, P. Silventoinen and O. Pyrhonen, "Dual three-phase permanent magnet synchronous machine supplied by two independent voltage source inverters," Proc. Int. Symp. Power Electron.Electr. Drives, Autom.and Motion, pp.741-747, 2012

\section{BIOGRAPHIES OF AUTHORS}

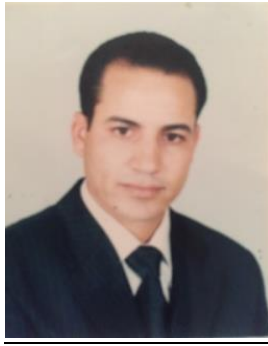

Mhammed Hasoun: was born in Khouribga Morocco in 1969. He received the Engineering degree in 1995 from Navy Royal School, Military Navy, Casablanca, Morocco; and the certificate of Navy Safety in 1996 at Cherbourg, France. From 1996 to 2008, he occupied the function of propulsion engineering chief in military ships various. In 2008 he joined the Navy Royal School, where he is currently professor at the Engineering Department. His current research interests are in the application of power electronics converters and motor drives for electric propulsion systems. Email: mhammedhasoun@gmail.com 

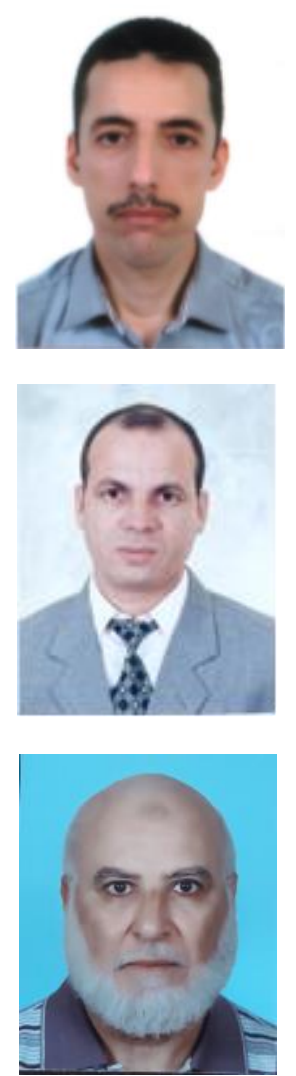

Aziz El Afia: He received B.Sc., M. Sc. degrees from Hassan II University, Casablanca in 1990, 1994 respectively and the Ph.D. degree in Electrical Engineering from The National High School of Electrical and Mechanical Engineering (ENSEM), Hassan II University, Casablanca in 2009. Since 2011 he has been working as a Professor of Power Electronic at the National High School of Arts and Crafts of Casablanca (ENSAM). His current research interests are in power electronics converters and control of machines and drives for application from automotive to renewable energy. Email: aziz.elafia@univh2c.ma

Mohamed Khafallah: was born in Morocco in 1964. He received B.Sc., M.Sc. and Doctorate degrees from Hassan II University, Casablanca, in 1989, 1991 and 1995 respectively, all in Electrical Engineering. In 1995 he joined the National High School of Electricity and Mechanics (ENSEM), Hassan II University, Casablanca, Morocco, where he is currently professor tutor in the Department Electrical Engineering and chief of Laboratory Energy and Electrical Systems (LESE). His main research interests the application of power electronics converts and motor drives. He has published a lot of research papers in international journals, conference proceedings as well as chapters of books. Email: m.khafallah@gmail.com

Karim Benkirane: was born in Morocco in 1960. He received B.Sc., M.Sc. and Doctorate degrees from Mohamed V University Rabat and University of Sciences and Technics at Languedoc (USTL), France, in 1978, 1983 and 1986 respectively, all in Electronics Engineering. In 1987 he joined the Royal Navy School (ERN), Casablanca, Morocco, where he is currently professor tutor in the Department Research. His main research interests the application of power electronics converts and motor drives. He has published a lot of research papers in international journals. Email: karbenkirane@yahoo.fr 